\title{
LA DIMENSIÓN ÉTICA DE LA CRISIS MEDIOAMBIENTAL. PROPUESTAS PEDAGÓGICAS
}

\author{
The ethical dimension of the environment crisis. Pedagogic \\ proposals
}

La dimension éthique de la crise de l'environnement.
Propositions pédagogiques

Pedro Ortega Ruiz y Eduardo Romero SÁnchez

Universidad de Murcia. Facultad de Educación. Departamento de Teoría e Historia de la Educación. Campus Universitario de Espinardo. Apartado de Correos 4021.30071, Murcia. Correo-e: portega@um.es

Fecha de recepción: enero de 2009

Fecha de aceptación definitiva: abril de 2009

Biblid [(1130-3743) 21, 1, 2009, 161-178]

RESUMEN

El trabajo aborda el problema ambiental desde una perspectiva moral, como tesis central. Se justifica la necesidad de un nuevo enfoque del problema medioambiental que supere los planteamientos estrictamente ecológicos en los que estamos instalados. Destacan el valor intrínseco de la naturaleza y la necesidad de cambiar nuestras relaciones con ella. Por último, se ofrecen unas propuestas educativas que podrían favorecer unas relaciones más respetuosas de los humanos con la naturaleza.

Palabras clave: desarrollo sostenible, ética, valor, educación moral, educación ambiental. 


\section{SUMMARY}

This paper tackles the environmental problem from a moral perspective as its main argument. It justifies the need for a new focus on the environmental problem which goes beyond the strictly ecological approaches in which we are set. The intrinsic value of nature and the need to change our relationship with it are highlighted. Finally, some educational proposals are put forward which could encourage more respectable human attitudes towards nature.

Key words: sustainable development, ethics, value, moral education, environmental education.

\section{SOMMAIRE}

Ce travail aborde le problème de l'environnement d'un point de vue moral comme thèse centrale. Le besoin d'une nouvelle démarche concernant le problème environnemental qui dépasse les approches strictement écologiques dans lesquelles nous nous trouvons est démontré. La valeur intrinsèque de la nature et le besoin de changer nos relations avec elles sont soulignées. Enfin, des propositions éducatives qui pourraient favoriser des relations plus respectueuses des êtres humains avec la nature sont présentées.

Mots clés: développement durable, éthique, valeur, éducation morale, éducation environnementale.

\section{INTRODUCCIÓN}

Los medios de comunicación y la literatura alarmista nos informan, casi a diario, de las múltiples desgracias que, como plagas bíblicas, amenazan a nuestra calidad de vida y, a veces, a la misma supervivencia de nuestra especie. En el centro de esta inquietud sólo se contempla el futuro de la humanidad, la suerte que podamos correr los humanos con el progresivo deterioro medioambiental. En este trabajo no queremos contribuir a mantener este discurso de muy corto recorrido para afrontar, en su raíz, el problema medioambiental. Por el contrario, pretendemos ayudar, a través de la educación, a que los humanos nos sintamos solidarios e interdependientes en una comunidad de vivientes de la que formamos parte; que esa comunidad de vivientes va más allá de lo que el hombre controla o remodela con sus creaciones culturales; que inevitablemente los humanos compartimos suerte y destino con múltiples compañeros de viaje; y que éstas son convicciones sobre las que se sustenta cualquier relación responsable, es decir, moral del hombre con la naturaleza (Gómez-Heras, 1997). No creemos que sea lo más urgente, desde la educación ambiental, seguir "informando" de los peligros que nos acechan por el preocupante deterioro ambiental. La sociedad está suficientemente informada 
de la degradación medioambiental. Necesita más bien "mirar de otra manera a la naturaleza", establecer lazos de relación más cordiales con ella. El hombre de nuestros días necesita situarse en la naturaleza como uno más que comparte con los otros seres vivos la tarea de seguir existiendo, a pesar de todo. Esto conlleva un cambio en nuestro estilo de vida mediante el cambio de actitudes y la apropiación de valores morales que sitúa al conjunto de la naturaleza en nuestro horizonte moral. Para este objetivo, no es suficiente la aportación de la ecología y de otras ciencias. Es una tarea que se resuelve mediante un prolongado proceso educativo. Sin un cambio en nuestro modo de relacionarnos con la naturaleza, en nuestra cultura ecológica, todo intento de hacer frente a los problemas medioambientales acabará por reproducir, tarde o temprano, los mismos problemas que ahora intentamos superar. Esto llama a una ética y a una educación ambiental que tengan como punto de partida la consideración (valoración) moral del conjunto de los seres vivos, superando un paradigma (antropocéntrico) que se ha mostrado insuficiente para dar cuenta de la dignidad de la naturaleza.

\section{LA COMPLeJidad DE LA CRISIS MEDiOAMBIENTAL}

La crisis medioambiental de nuestra civilización arranca del momento mismo en que el hombre se aparta drásticamente de la sabiduría de la Naturaleza, y aumenta a medida que el distanciamiento crece (Gómez Gutiérrez, 2004, 241).

El grave problema que nos plantea la crisis medioambiental es tanto más grave y complejo cuanto que viene acompañada de otra crisis más profunda: el modelo de sociedad en el que estamos instalados en el mundo desarrollado, por lo que deberíamos hablar no ya tanto de crisis ambiental cuanto de crisis de sociedad. Lo paradójico es que los efectos ambientales producidos no empiezan y acaban en esta parte del mundo del bienestar, sino que se extienden también a aquellos países ajenos a nuestro "desarrollo". Para gran parte de la población terrestre, el significado positivo de la palabra "desarrollo", profundamente arraigado tras dos centurias de construcción social, es un recordatorio de lo que no son (Esteva, 1999). Abordar la crisis medioambiental desde todas las variables que inciden en ella es una tarea difícil y compleja, porque la complejidad es una de las características que mejor la definen. De una u otra manera todas las actividades humanas están siendo afectadas por ella. La crisis ambiental excede el ámbito de lo estrictamente ecológico y afecta a los planos político, social y económico. En la era de la globalización ya no es posible sustraer un problema a la influencia de otros problemas, todo aparece interrelacionado (Papastephanou, 2005). Y ésta es la clave para entender esta crisis, si sabemos ubicarla "en el marco de una crisis de mayor amplitud que afecta a los pilares del proyecto civilizador de la modernidad" (Caride y Meira, 2001, 36).

La relación entre el ser humano y la biosfera ha sido durante milenios pacífica y ha permitido el equilibrio entre todos los ecosistemas. A partir de 
la industrialización y el imparable desarrollo tecnológico, esta relación podría definirse como conflictiva. La capacidad tecnológica de la sociedad actual en el uso y transformación de la energía, la sobreexplotación de los recursos naturales, la superproducción y la manipulación genética de alimentos, el uso intensivo de productos químicos en la agricultura, con sus posibles consecuencias en la alteración del genoma y comportamiento humanos, ha llevado al extremo el proyecto "civilizatorio" de la modernidad en el dominio de la Naturaleza. Tal grado de desequilibrios ha sobrepasado la capacidad de "acogida" o asimilación por parte de la biosfera, y la reacción se ha hecho inevitable. La crisis ecológica ha derribado una de las ideas ilustradas más exitosas: la idea de "progreso", obligando a la sociedad moderna a desprenderse de una seña de identidad que la hacía apetecible para todos. Al mismo tiempo, el proceso acelerado de desconfianza ante los efectos deshumanizadores de la tecnociencia y el rostro menos "amable" de un descontrolado desarrollo industrial, paradójicamente, nos han obligado a mirar de frente a la naturaleza y a estrechar lazos de complicidad con ella.

A partir de la década de los setenta se fortalece un discurso que vincula el desarrollo económico y el cuidado de la naturaleza; que el bienestar de la humanidad está indisolublemente vinculado al desarrollo con la naturaleza; que se hace inaplazable un contrato natural basado en la alianza de la ciencia, el desarrollo y la preservación del medio ambiente (Mayor Zaragoza, 2001). Si en las décadas pasadas se nos había enseñado a pensar y vivir en un mundo de recursos naturales inagotables, ilimitados, los sucesivos Informes del Club de Roma: Los Limites del crecimiento (1975), Factor 4 (1997) y Nuestro futuro común (1992), y las Declaraciones de los Organismos de la Comunidad Europea (Saura y Hernández Prados, 2008) nos advierten que los recursos naturales son limitados y que los residuos producidos por el consumo cada vez mayor de energía y materias primas ponen en peligro la capacidad de absorción del ecosistema. Hasta ahora, la respuesta más frecuente a esta situación de "emergencia ambiental" se ha limitado a la restauración de los daños producidos y a la prevención de los fenómenos de degradación del medio ambiente. Pero esta respuesta, aun siendo necesaria, se está viendo del todo insuficiente porque deja intactas las causas que producen el problema ambiental: 1) de una parte, una concepción de las relaciones ser humano-naturaleza fundada en el dominio y explotación, aún presente; y 2) de otra, el sistema económico de producción y distribución de las riquezas que está generando la sobreexplotación de los recursos naturales en los países pobres y su inevitable degradación. Son estos dos factores los que se han de modificar para cambiar las "condiciones ambientales" y afrontar adecuadamente la crisis ambiental que nos afecta. Se hace indispensable descubrir las relaciones sistémicas que existen entre la degradación del medio ambiente y las actitudes, valores y estilos de vida que se mantienen en el sistema económico dominante que gobierna las relaciones de producción y distribución de las riquezas.

Si hasta hace pocas décadas el problema ambiental era percibido como algo local, limitado en sus efectos a las fronteras de un país o región, ahora, en cambio, 
es asumido por todos, y forma parte de la conciencia colectiva, que el medio y su alteración o protección tiene consecuencias globales (Papastephanou, 2005).

Antes, cuando los pueblos vivían aislados, traspasar los umbrales de la sostenibilidad sólo tenía consecuencias reducidas al ámbito de lo local. Hoy, en cambio, en la era de la globalización de la economía, la técnica y la información, traspasar un umbral en un país puede suponer añadir dificultades y problemas en otros países (Ortega y Mínguez, 2001, 162).

La Tierra se nos ha quedado demasiado pequeña, y nuestro horizonte visual y moral ya no acaba en la inmediatez de las fronteras o límites de nuestra región o país, sino que se extiende a cualquier lugar del planeta que antes sólo lo contemplábamos en nuestra fantasía. El problema ambiental, y su adecuada respuesta, también se ha globalizado, ha pasado a ser un fenómeno y un tema de nuestro tiempo. Pero no siempre este problema global se ha tratado adecuadamente. Existe una determinada literatura (alarmista) muy influyente en la conciencia colectiva que ha creado una imagen distorsionada de la acción humana sobre la naturaleza, presentando al hombre como enemigo irreconciliable de nuestro planeta, depredador irredento de su medio. El deterioro del medio ambiente se ha dado siempre, desde el momento mismo en que el ser humano encontró un modo de vida sedentario y con él la necesidad de transformar su medio, trabajar y explotar la tierra para sobrevivir. Es la única especie animal que es capaz de alterar el equilibrio de los ecosistemas. Las demás especies se adaptan a un medio ya dado. El ser humano, por el contrario, lo tiene que crear, y por lo tanto transformar y, no pocas veces, peligrosamente alterar. Durante milenios la especie humana ha sido capaz de vivir en paz con la naturaleza, en un perfecto equilibrio con los ecosistemas. No es inevitable, por tanto, la agresión y degradación del medio, ni es incompatible la convivencia de nuevas formas de vida en los humanos con el cuidado y respeto hacia el resto de los seres vivos. No defendemos un retorno a una naturaleza idílica, ni instaurar una imagen angelical del ser humano, ello significaría desnaturalizarlo, negarle su condición inherente de animal cultural, y en tanto que cultural, también transformador del medio y del paisaje. "Restaurar", "retornar" al seno de una naturaleza "buena", es, tal vez, lo que hay de más peligroso en los discursos de la educación ambiental. Nos situaría en un discurso que inconscientemente deifica a la naturaleza, o la humaniza hasta el punto de establecer un continuum entre ser humano y naturaleza. Tal discurso no es otra cosa que una encubierta desvalorización de todo lo que no sea humano. Tal es la posición de Rombach (2004, 110): "Todo es humano, aunque de una manera menos pronunciada. Sólo hay una constitución ontológica fundamental que es representada por lo bumanum; así, todo participa de lo humano, se dirige al hombre de un modo humano, y comparte con él la misma realidad". No se trata ni de ser siervos ni dioses en la relación con la naturaleza, sino de reconocer: a) que la acción transformadora del ser humano, en las últimas décadas, ha roto el equilibrio ecológico durante tantos siglos mantenido; b) que las alteraciones producidas desbordan ya 
las capacidades del sistema para asimilar el cambio; c) que sólo con la llegada de la revolución industrial y el espectacular desarrollo científico y tecnológico de los últimos decenios, la humanidad ha perdido la paz ecológica en la que había vivido durante siglos. En el discurso medioambiental es necesario precisar el sentido de los términos que se utilizan y evitar la "demonización" de algunos de ellos. Así, la alteración (inevitable) del medio no puede seguir siendo vista como algo en sí mismo negativo, a no ser que lo que se esté postulando sea la vuelta al paraíso perdido, al jardín del Edén, desde una concepción mítica de la naturaleza, en la que, al parecer, caen no pocos defensores del medio ambiente (Ortega y Mínguez, 2003). Sólo los desmanes en la explotación de la naturaleza, producida con el acelerado desarrollo industrial, han generado los peligros para los ecosistemas, no la inevitable alteración del medio por la acción del ser humano que, desde su sedentarización, se ha estado produciendo.

\section{LA DIMENSIÓN ÉTICA DE LA CRISIS MEDIOAMBIENTAL}

Nos resulta difícil admitir, por ahora, la reciprocidad de ser humano y naturaleza en una relación moral simétrica. Ésta sólo es posible entre iguales desde un igualitarismo biótico profundo, como sostiene Naess (1984). Pero tampoco es asumible, por nuestra parte, la consideración de los seres vivos como carentes de valor y, por lo tanto, de aprecio y estima, de relevancia moral. Defendemos que son seres que por sí y de sí merecen nuestro reconocimiento o nuestro respeto (que valen), que se traduce en actitudes y comportamientos de protección y cuidado (en inglés, care), en una relación ética o de responsabilidad hacia ellos, independientemente de que nos reporten algún beneficio o utilidad. Y tienen valor (es decir, valen), no porque nosotros, en un acto de gratuidad, hagamos donación de este reconocimiento y sólo por esto sean dignos o "valgan". El reconocimiento y respeto, su valor moral es más bien exigido desde su valiosidad intrínseca. Ésta no está vinculada a la capacidad de comunicación en un lenguaje hablado, como la entendemos en los seres racionales. También los otros seres animales no racionales expresan y suscitan sentimientos, y es otra forma de comunicación con los otros. "Los elementos y sus sistemas tienen derecho a existir y a funcionar, pero también a replicarse y permanecer. Es, por tanto, reprobable todo cuanto dificulte la continuidad de cualquiera de los elementos del sistema" (Gómez Gutiérrez, 2004, 247). Por ello, nos distanciamos del denominado antropocentrismo "débil", porque enmascara aquello que en el antropocentrismo "fuerte" aparece explícitamente afirmado: la condición exclusiva del ser humano como referente moral. Cualquier forma de antropocentrismo descansa en una visión jerarquizada de la naturaleza tan presente en la literatura y en la conciencia colectiva, cuando la trama de la vida está constituida por redes dentro de redes, no por individuos aislados distribuidos jerárquicamente. Tendemos a organizar las redes (sistemas) «en un esquema jerárquico, situando los mayores por encima de los menores a modo 
de pirámide invertida, pero esto no es más que una proyección humana. En la naturaleza no hay un "arriba" ni un "abajo" ni se dan jerarquías. Sólo hay redes dentro de redes" (Capra, 2002, 54-55).

Por ahora, la reflexión actual sobre la ética ambiental y la responsabilidad de los seres humanos hacia el medio ambiente no permite hacer otro discurso sobre la naturaleza de la moralidad entre los seres humanos y el medio natural no-humano. Ya es suficiente que, excluyendo todo maximalismo o visión mítica de la naturaleza, se aborde, desde el rigor, un desarrollo sostenible del planeta que permita restaurar el daño ecológico producido, y preservar, en el futuro, las condiciones de vida de todos los ecosistemas, no pensando sólo en la supervivencia de la especie humana, sino en el deber moral de mirar y tratar "de otro modo" a los demás seres vivos (Ortega y Mínguez, 2003). En la actualidad, ya no es posible entender el deterioro ambiental al margen de las relaciones existentes entre todos los elementos que constituyen el sistema Naturaleza. "La Naturaleza funciona como una red de relaciones intrínsecamente dinámicas, donde las propiedades de las partes que forman un sistema particular sólo pueden ser entendidas a partir de la dinámica de todo el conjunto" (Caride y Meira, 2001, 67). Y no es acertado analizar la crisis ambiental desde categorías exclusiva o predominantemente naturales, situando el problema en el ámbito exclusivo del discurso ecológico. De este modo, el discurso sobre el problema medioambiental consideraría, involuntariamente, al ser humano sólo como aparato orgánico, y convertiría la discusión ambiental en un discurso natural sin el ser humano, sin la cuestión del significado sociocultural y moral, argumentando desde concepciones tecnocráticas y naturalistas. Éstas

se agotan en el intercambio y la evocación de las sustancias nocivas que contienen el aire, el agua y los alimentos, de cifras relativas de crecimiento demográfico, de consumo energético, de demanda de alimentos, de falta de materias primas, etc., con un celo y exclusividad como si nunca hubiera habido alguien (por ejemplo, un tal Max Weber) que hubiera dedicado su tiempo a mostrar que si no tomamos en consideración las estructuras sociales de poder y de reparto, las burocracias, las normas y racionalidades dominantes, todo esto es vacío y absurdo (probablemente, ambas cosas) (Beck, 2001, 30).

La crisis medioambiental es ante todo una crisis social, un problema político y económico y, en su raíz, un problema moral (Wiredu, 2005; Öhman, 2006).

Hasta ahora la preocupación medioambiental se ha centrado en la preservación o conservación de la salud del planeta como condición para un desarrollo sostenible del primer mundo. Hoy se asume, al menos en el ámbito de las formulaciones políticas, que el desarrollo sostenible del planeta no es posible si aquél no es extensible a todos (Murga Menoyo, 2008), si socialmente no es compartido entre toda la comunidad humana. El sentido de desarrollo sostenible no puede menos que subrayar la necesaria interrelación entre los sistemas biológicos, económicos y los sociales. Desarrollo ecológico sostenible aparece ya asociado a desarrollo socialmente también sostenible (Redclift, 2000). Es evidente que la crisis 
medioambiental no es ideológicamente neutra, ni ajena a los intereses económicos y sociales. Los problemas ambientales son de naturaleza política antes que técnica; son construcciones sociales que afectan a la calidad de la vida o a las necesidades sociales de los ciudadanos (Caride y Meira, 2001), por lo que cualquier estrategia que intente abordar el problema, en su raíz, necesariamente lo debe contemplar en su contexto sociopolítico y moral, es decir, a partir de las estructuras políticas y económicas y de la conciencia moral imperantes que explican la crisis medio ambiental. Los intentos de "naturalizar" el problema, presentándolo como resultado inevitable de un proceso que por sí mismo es capaz de controlar y asumir las externalidades del desarrollo, y que pretenden encontrar la respuesta adecuada en la investigación científica, sólo pueden alargar y ahondar aún más las negativas consecuencias de un crecimiento económico que ha olvidado la dimensión sociomoral y sostenible del desarrollo. La crisis medioambiental es inseparable de la crisis civilizatoria. Es la civilización de los medios que ha subordinado el progreso y el desarrollo económico no a la adaptación de los seres humanos al medio natural, sino a la adaptación del medio a las necesidades humanas creadas por el crecimiento económico ilimitado. No asistimos, por tanto, a un problema técnico, de medios, que técnicamente se haya de resolver, sino a un problema de fines de naturaleza social y moral. «El problema radica en la relación existente entre consumo y calidad de vida, y la diferencia, cada vez mayor, entre los dos mundos marcados por la riqueza y la pobreza" (Azcárate y Mingorance, 2003, 217). Por ello es indispensable reconocer que es imposible establecer unas relaciones armónicas (ecológicas) del ser humano con la naturaleza, y abordar adecuadamente el problema medioambiental, si no existen al mismo tiempo unas relaciones justas, éticas entre los seres humanos (Bellver, 2000). Ética y protección o cuidado del medio ambiente son indisociables.

\section{LA EDUCACIÓN MORAL COMO RESPUESTA A LA CRISIS MEDIOAMBIENTAL}

La respuesta al problema medioambiental se ha circunscrito, casi siempre, al ámbito de la ecología, como si ella abarcase todas las formas posibles de abordar este problema. De este modo, se ha actuado desde un reduccionismo científico que sólo ha visto causas del deterioro ambiental que podrían ser contempladas del modo más adecuado en el ámbito de la ciencia. Otros autores (Sosa, 1990; Sempere, 1999; Gómez-Heras, 2000; Colom, 2000; Wiredu, 2005) encuentran respuestas a la grave situación de degradación medioambiental que van más allá del planteamiento que pudiera hacer un ecologista preocupado por la conservación de la fauna y de la flora. Su línea de argumentación tiene una profunda carga social y moral: la crisis medioambiental, además de ser un problema de fuerte desequilibrio entre Norte y Sur, como sostiene Sempere (1999), es también un problema moral, cuya respuesta encuentra su lugar más adecuado en la formación de ciudadanos que valoren y aprecien la naturaleza y se sientan solidarios de las generaciones presentes y futuras en el uso racional de los recursos naturales disponibles. 
Los problemas a los que hoy se enfrenta la humanidad no requieren tanto soluciones tecnológicas (que también), cuanto una reorientación ético-moral de los principios que regulan las relaciones entre los hombres y las relaciones de éstos con la naturaleza (Ortega y Mínguez, 2001). La primacía de la razón técnico-estratégica, tendente a la eficacia, el éxito y el provecho ha monopolizado todas las formas de la racionalidad. La "razón conforme a resultados" se ha convertido para el hombre moderno en el criterio principal, cuando no el único, que decide y justifica, en la práctica, los comportamientos sociales y las relaciones económicas y políticas entre las naciones. Esta racionalidad está en el origen de la crisis ambiental que nos afecta. La naturaleza ya no es vista como un valor o sujeto de aprecio, sino como objeto de dominio. La progresiva racionalización de la sociedad, vinculada a la institucionalización del progreso científico y tecnológico, no ha ido acompañada por un sentido antropológico originario y gratuito en las relaciones humanas. Se diría que desarrollo humano y desarrollo científico y técnico han seguido caminos divergentes, cuando no enfrentados. Dos concepciones bien diferenciadas del mundo, sustentadas una sobre la racionalidad axiológica y otra sobre la tecnológica-instrumental, han entrado en conflicto. "Las propias ideas (en el sentido kantiano) se ven arrastradas por el remolino de la cosificación; hipostatizadas y convertidas en fines absolutos, sólo tienen ya un significado funcional para otros fines" (Habermas, 1996, 140). Por ello consideramos que es necesario abordar la crisis medioambiental desde un enfoque distinto que sea capaz de vincular la racionalidad técnico-científica con la racionalidad axiológica, no sólo en cuanto que ésta es dimensión esencial de la acción humana, sino también en cuanto que la naturaleza es ella misma un valor y sujeto de valores. Es la respuesta más sensata para que la capacidad destructiva de los valores morales, inmanente a la racionalidad instrumental y a su idea de progreso, se desvincule del servicio a los intereses económicos o estrategias políticas que solamente se orientan al provecho y al lucro (Gómez-Heras, 1997).

El problema medioambiental, en su dimensión ética, tiene mucho que ver con la capacidad y actitud de asumir responsabilidades frente a los demás, presentes y futuros, desde el convencimiento de que hay cosas (recursos naturales) que no son de uso exclusivo, sino que a todos pertenecen. Y que hay también formas diversas de vida que en sí mismas merecen toda nuestra estima y nuestro respeto, y son dignas de reconocimiento y valor, independientemente de la utilidad que puedan reportar a los seres humanos. Esta nueva ética medioambiental exige no sólo ampliar las relaciones morales con los demás más allá de las relaciones inmediatas yo-tú, sino también entenderlas en el inevitable contexto de las relaciones con, en y a través de la naturaleza o medio. No compartimos la heurística del miedo con la que H. Jonas (1995) encauza una hermenéutica del futuro, no en el horizonte de la esperanza, sino en una forma mitigada de la angustia y del temor. Con ello Jonas convierte al miedo en soporte de una nueva conciencia moral. Más bien, nos situamos en la heurística de la complicidad y del cuidado en la que la tarea de vivir es compartida por toda la comunidad de los seres vivos, humanos y 
no-humanos, en una interacción mucho más profunda de lo que a primera vista pudiera parecer.

Nuestra propuesta de actuación sobre el problema medioambiental incide, a la vez, en el uso progresivo de energías alternativas procedentes de fuentes renovables y menos agresivas al medio, y en la promoción de una cultura fundamentada en la justicia y la solidaridad como valores morales. Ambas actuaciones deben ir unidas: una, para que propicie la detención y corrección de los daños ecológicos; y otra, para que haga posible un cambio de cultura a favor de la naturaleza. Las propuestas exclusivamente técnicas basadas en los estudios científicos sobre el deterioro del medio, pérdida de la capa de ozono, contaminación, degradación del suelo, deforestación, etc., con ser necesarias, son del todo insuficientes para afrontar el problema en su raíz. "Si no se pone límites a la carrera de acumulación de privilegios en una parte del planeta a costa de la extrema pobreza de la otra, no será posible detener el deterioro ambiental" (Ortega y Mínguez, 2001, 167). La injusta distribución de la riqueza y la división del mundo en dos grandes polos: uno, el de la prosperidad y bienestar; y otro, el de la pobreza y la dependencia también tienen mucho que decir sobre el problema medioambiental. Y esta situación sociopolítica no encuentra respuesta adecuada en soluciones técnicas, sino en comportamientos morales (Öhman, 2006).

\section{Propuestas pedagógicas}

Educar para una cultura medioambiental exige: a) equipar a los ciudadanos para proteger y conservar los recursos naturales, para admirar y amar todas las formas de vida en su conjunto; b) tomar conciencia de que "la preocupación por los demás incluye muy en primer término el cuidado y la mejora del medio ambiente en el que todos, ahora y mañana, estamos llamados a vivir" (Rodríguez, Bernal y Urpi, 2005, 205); y c) "desmercantilizar" las relaciones interpersonales y reivindicar la cultura del don en la consideración de los bienes de la naturaleza. Una nueva cultura medioambiental, basada en la ética, conlleva un profundo cambio de actitudes y el aprendizaje de nuevos valores, es decir, situarse ante el problema medioambiental "desde otro modo de pensar" (Bonnett, 2003). Y esto ya supone un nuevo equipaje ético, una nueva ética global que oriente las actuaciones de los individuos y de los pueblos. Estos cambios de actitudes y aprendizaje de nuevos valores son requisitos indispensables para la puesta en práctica de medidas eficaces y de iniciativas sociales. "Son las chispas que encienden los procesos de cambio" (Sosa, 2000, 282). Es obvio que un cambio en las relaciones de los seres humanos con su medio no se va a dar sin un cambio en las escalas de valores dominantes en la sociedad, es decir, sin un cambio cultural y estilo de vida. Y sin un cambio cultural, todo intento de dar repuesta eficaz a los problemas medioambientales acabará por reproducir, más tarde, los mismos problemas que ahora se intenta resolver (Ortega y Mínguez, 2001). 
Estas nuevas relaciones con la naturaleza demandan un nuevo enfoque en la educación ambiental (Ortega y Mínguez, 2003). Uno de los planteamientos más habituales en el tratamiento del problema medioambiental ha consistido en poner de relieve el daño producido por la acción humana sobre nuestro ecosistema con la consiguiente amenaza de trastocar el delicado equilibrio de la vida en el planeta Tierra. Los distintos programas de educación ambiental han acentuado el papel de la "información" sobre los desastres ecológicos producidos por la actividad humana. Siendo esto imprescindible, se ha considerado que la sola información sobre los problemas medioambientales sería suficiente, por sí misma, para evitar tales acciones rechazables por ser dañinas al medio ambiente; y con ello se ha evitado "actuar de otro modo" para que no se produzca un mayor daño ecológico. Con esta orientación cognitivista se ha pretendido potenciar la capacidad racional de los educandos para que actúen de modo coherente con los conocimientos o informaciones que se les han transmitido. Sin embargo, la información sobre los daños ocasionados a la naturaleza o sobre los peligros que nos acechan por la degradación ambiental no nos ha conducido a un cambio en el estilo de vida y en los sistemas de producción. Al insistir tanto en el componente cognitivo a la hora de afrontar el problema medioambiental, se ha marginado, con ello, una de las claves decisivas para que el comportamiento humano actúe del modo deseado: el mundo de los significados personales a través de los cuales expresamos toda nuestra experiencia, es decir, las creencias y los valores concretos que animan nuestra existencia. De este modo, se hace difícil "otra educación ambiental" si no se atiende, junto a los conocimientos, la dimensión afectiva, valorativa; si no está presente el componente moral que debe impregnar nuestras relaciones con la naturaleza.

Esta nueva relación exige una praxis educativa que permita:

4.1. Situar el componente ético-moral en nuestra relación con la naturaleza. Se trata de abrir una nueva perspectiva en la relación ser humano-naturaleza más allá de una mentalidad científica y tecnológica, en la que las formas de existencia, humana y no humana, tienen valor intrínseco. La naturaleza y lo humano son moralmente relevantes porque son valiosas en sí mismas. Ello implica, de una parte, el reconocimiento de que todos los individuos comparten una misma biosfera y su destino está estrechamente interrelacionado por las acciones humanas realizadas en cualquier espacio y tiempo. Lo que obliga, por un lado, a adoptar una perspectiva planetaria de los problemas medioambientales y no limitarnos a la sola visión instantánea y localista de los mismos. Por otro, a otorgar valor intrínseco a los seres no humanos (vivos o no), alejado de toda consideración "Sagrada" o "mítica" de los mismos (biocentrismo exagerado), como también de considerarlos como una entidad estrictamente instrumental (antropocentrismo exagerado). La educación ambiental exige, por tanto, el desarrollo de una conciencia moral que impida la explotación ilimitada y abuso humano de los bienes de la naturaleza; el aprendizaje de 
una competencia moral que permita al ser humano situarse como alguien responsable de mantener las adecuadas condiciones de vida para todos los seres vivos.

4.2. Pasar del "yo-naturaleza" al "nosotros-naturaleza". Conocer qué sabemos y pensamos sobre el medio natural no lleva necesariamente a amar y valorar más la naturaleza. Una mayor información no conduce necesariamente a una conducta más respetuosa del medio natural (Murga Menoyo, 2008). Pensar desde la lógica de lo peor, de los desastres naturales, induce a largo plazo a conductas de deserción personal y de inevitable fatalidad ecológica. Se debe evitar el excesivo intelectualismo de corte catastrofista acerca del problema medioambiental para dar un mayor protagonismo a las conductas positivas que orienten actuaciones en el medio ambiente. Este protagonismo se enmarca dentro de una relación moral entre "el yo y lo otro", una relación de alteridad. Educar a los ciudadanos para que sean responsables de su conducta ante la naturaleza implica la toma de conciencia de que "lo otro", y con ello "los otros", no pueden sernos indiferentes. Cuando "lo otro" desaparece del horizonte ético de las conductas humanas se produce un olvido y, a la larga, su aniquilación. Por ello, educar desde esta perspectiva consiste en el desarrollo de la capacidad de apertura y de respuesta a la demanda que viene de fuera, de lo otro (lo natural) y los otros (actuales o futuros). Ello implica la capacidad de percibir que nuestro entorno es la biosfera, casa común de todos, que "el hombre no es un escapado de la naturaleza, un huido, un extranatural" (García Carrasco, 2007, 222). Esta ampliación del espacio natural y moral desborda la relación del "yo-naturaleza" para circunscribirla en la perspectiva del "nosotros-naturaleza". Permite, por otra parte, un reencuentro con la naturaleza, no del observador "curioso", sino de aquel que se siente parte de ella, o mejor dicho, que se siente y se reconoce naturaleza. Pero este reencuentro con la naturaleza "exige una demolición y una reedificación de creencias, supone cambiar nuestras imágenes, extender nuestros focos de atención, incrementar los centros de interés" (García Carrasco, 2007, 222) como tarea ineludible de una propuesta de educación ambiental. Comprender que también los humanos somos naturaleza constituye un objetivo fundamental de la educación ambiental. Limitar la acción educativa a una tarea de bumanización en el ámbito exclusivo de nuestras relaciones con los humanos (Gil Cantero, 2008), ignorando nuestras responsabilidades con el resto de los seres no-humanos, responde a una concepción reduccionista de la educación de muy corto alcance.

4.3. Cambiar nuestra cultura de enseñar. Ser persona moral ante los desafíos del medio ambiente significa responder de lo otro como tarea permanente. El aprendizaje de la conducta responsable (moral) hacia el medio natural no se limita a una acción encerrada en el tiempo y en el espacio escolar. Siendo la escuela un lugar idóneo, el desarrollo de dicha competencia moral debe 
hacerse experiencia valiosa también en otros espacios. Hacerse cargo de lo otro, asumir la responsabilidad del entorno social y natural implica educar en y para el compromiso ético y político que desborda los muros del aula. Y entonces la educación se hace denuncia de aquellas acciones y estructuras socioeconómicas que degradan el bien común de la naturaleza y se rescata el núcleo esencial de la educación: su dimensión ética y política.

4.4. Buscarel bien común. El problema medioambiental no reconoce fronteras, sino que trasciende los espacios administrativos arbitrariamente establecidos. Ello demanda una acción educativa que responda al carácter global del problema. Es verdad que toda acción educativa está necesariamente "localizada" en un medio, en un tiempo y espacio concretos (en "su" circunstancia), pero nunca deben obviarse las implicaciones globales que cualquier actuación humana tiene sobre el medio, tanto para su protección y conservación como para su deterioro o degradación. Resaltar esta perspectiva es una de las señas de identidad de la educación ambiental.

4.5. Promover la ciudadanía ecológica como una forma pacífica de vivir en la Tierra. Es un tipo de ciudadanía que estrecha vínculos morales (de responsabilidad) con el planeta y no sólo con los demás seres humanos. El ciudadano "ecológico" es conciudadano de desconocidos y de cercanos, pero no ajeno al arraigo específico a su espacio local en el que actúa desde una perspectiva siempre global (Velayos, 2004). Su compromiso con la Tierra está fundamentado en el respeto y el reconocimiento de la dignidad (valiosidad) en sí y por sí de nuestro planeta, no en la beurística del temor ("malum inminens") sobre los peligros que acarrea para la supervivencia de la especie humana la sobreexplotación de los recursos naturales y el empleo cumulativo y acelerado de la acción tecnológica, como nos la presenta H. Jonas, en una muestra más de la dificultad y resistencia a escapar de un omnipresente antropocentrismo. Existir, y existir con dignidad, es una tarea y un derecho que compete no sólo a los humanos, sino también al resto de los seres nohumanos. Nuestra existencia (humana) en dignidad está vinculada a que los demás seres también puedan ver reconocidos sus derechos a existir y vivir "en dignidad". La escala en la dignidad (valía y reconocimiento por los demás de tal valía) responde a unos valores que los humanos nos hemos atribuido, excluyendo a las demás especies del ámbito de lo valioso. De este modo, sólo el ser humano ha sido y se ha sentido reconocido como «ser digno", valioso.

4.6. Promover un desarrollo sostenible que equilibre el crecimiento económico y la defensa de la naturaleza, a la vez que permita la distribución justa de la riqueza y de la cultura. Satisfacer las necesidades básicas de todos es un fin inseparable de un desarrollo sostenible también para todos. Justicia y equidad no son principios incompatibles con el principio de la sostenibilidad. Pensar y actuar desde la sostenibilidad significa dar a la vida personal y 
colectiva un enfoque global, abarcador, que incide en todos los ámbitos: político, económico, social y moral. Confiar al solo crecimiento económico la universalización del bienestar y la erradicación de la pobreza no deja de ser un peligroso espejismo. "Un mayor crecimiento, del mismo estilo del que se ha producido en estas últimas décadas, no salvará a los pobres. Lo único que puede salvarlos son estrategias encaminadas a distribuir de manera más equitativa la renta y la riqueza" (Brown y otros, 1997, 121). El desarrollo es sostenible cuando éste es para la gente, de la gente y con la gente; cuando es de todos.

4.7. Cambiar el modelo de educación ambiental. Abandonar una pedagogía centrada sólo en el conocimiento y en la información, para dar paso a una educación que englobe a toda la persona. No es suficiente "informar" $\mathrm{y}$ "conocer" para propiciar un cambio en las relaciones del hombre con la naturaleza. Es indispensable formar en los educandos sentimientos de respeto, cuidado y amor a la naturaleza. La educación ambiental, como la educación cívica y moral, no debe centrarse sólo en contenidos conceptuales que se aprenden en una disciplina curricular. Implica, también, el aprendizaje de actitudes y valores que, como tales, exigen la "complicidad" de la comunidad educativa y del conjunto de la sociedad que hagan posibles experiencias observables de respeto, cuidado, protección y amor a la naturaleza. El inevitable componente moral de la educación ambiental rebasa las posibilidades de la pedagogía cognitiva. Los valores se aprenden desde y en la experiencia. Cuando ésta falta sólo se da discurso, del todo insuficiente para el aprendizaje del valor.

4.8. La educación ambiental debe ser global. La educación ambiental que propugnamos ha de hacerse en y desde la familia, la escuela y la ciudad, en el conjunto de la sociedad desde una concepción holista y global del problema medioambiental. Esta educación implica: a) la denuncia de las situaciones injustas en la distribución de las riquezas; b) el compromiso político para cambiar las estructuras socioeconómicas que generan la sobreexplotación de los recursos naturales; c) la formación para una ciudadanía ecológica que contemple la Tierra como la casa de todos los seres vivos por igual; y d) el equipamiento moral para un cambio en el estilo de vida más respetuoso con el conjunto de la naturaleza, empezando por el medio más próximo.

Ante la gravedad y magnitud del problema medioambiental, no es un despropósito afirmar que la cuestión siempre abierta de qué debe ser el hombre debe dar paso al primer mandamiento que se halla siempre en la base de aquella cuestión: que el hombre debe seguir existiendo, y con él la naturaleza (Ortega y Mínguez, 2001, 168).

La educación moral no debe limitarse al ámbito de las relaciones interpersonales, como sostiene la ética kantiana. Debe incidir en aquellas cuestiones en las que nuestro "interlocutor afectado" se sitúa en el campo no-humano, y que también 
reclama sus derechos a una vida digna en este planeta que es de todos. La educación ambiental cumpliría suficientemente con sus objetivos si fuese capaz de preparar a los jóvenes y adultos para responder a estas preguntas: ¿Es la Tierra una fuente de recursos para la supervivencia de los seres vivos, o es algo que vale en sí mismo, independientemente de que nos sea imprescindible para la vida? ¿Es la Tierra la "Casa" (oikos) que a todos los seres vivos nos cobija, o sólo los humanos tenemos legitimidad para decidir quiénes debemos vivir en ella?

No nos engañemos, escribe Gómez Gutiérrez (1997, 103), la verdadera ética demanda respeto para el resto de los organismos, para todos; lo demás es simplemente una manifestación del más puro e insano egocentrismo. Aceptarlo es tan necesario que en tanto no seamos capaces de aceptar y comprender este aparente despropósito, no hay nada que hacer. Es como aprender el abecedario para empezar a escribir.

\section{CONSIDERACIONES}

1. Quizás alguien pueda pensar que confiar a la educación moral la respuesta adecuada a la preocupante situación de degradación ambiental en la que nos vemos envueltos es una muestra clara de ingenuidad, si nos atenemos a la confianza que todavía genera la tecnociencia para enfrentarse al problema ambiental (Murga Menoyo, 2008). Nosotros pensamos que en el discurso y praxis educativas hay siempre no ingenuidad, pero sí un componente necesario de utopía; y pensamos, además, que siempre ha sido, y hoy sigue siendo, el instrumento más eficaz para el cambio social y político; pensamos, también, que las estructuras socioeconómicas no resisten al cambio en las ideas y valores que sustenta un pueblo o comunidad. Por ello, aplicar las propuestas educativas para una relación más responsable con la naturaleza no es más que continuar con una tarea que los hombres ya han practicado desde antiguo: la praxis de la educación que ha posibilitado la evolución de la humanidad y los grandes cambios en la historia (Colom, 2000). Quizás sólo podamos aspirar (y es mucho) a una alfabetización ecológica que nos ayude a aprender de la naturaleza. De los ecosistemas

no aprenderemos el lenguaje, la consciencia y la cultura, ni, por consiguiente, la justicia y la democracia, pero tampoco la codicia y la deshonestidad. Nada podemos aprender de los ecosistemas sobre estos valores. Pero lo que sí podemos y debemos aprender de ellos es cómo vivir sosteniblemente (Capra, 2002, 307-308).

2. El discurso pedagógico ha estado demasiado subordinado al discurso ecológico, cuando no diluido en éste, al abordar el problema medioambiental. No afirmamos, ni pensamos obviamente, que la educación moral sea la única respuesta posible al grave deterioro medioambiental que padecemos, pero sí una respuesta imprescindible, pues todas las perversiones de la conducta humana con 
la naturaleza tienen una raíz moral: la disociación profunda entre lo que podemos hacer (técnica) y lo que debemos hacer (ética) (Gómez Heras, 1997). No hay cambio en la conducta humana respecto a la naturaleza si no hay cambio en nuestras actitudes y creencias, en nuestro estilo de vida, en nuestras ideas y valoraciones acerca de la naturaleza, durante siglos enraizadas en nuestra cultura. Y este cambio está vinculado a prolongados procesos educativos que permitan el cambio de actitudes y de creencias, y la apropiación o aprendizaje de valores morales, como la solidaridad inter e intrageneracional con los humanos y la responsabilidad moral hacia todas las formas de vida en cuanto realidades en sí mismas valiosas.

3. Habría que apostar decididamente por el paradigma biocéntrico como soporte teórico de la educación ambiental si se quiere ir al fondo del problema medioambiental. No es sólo la especie humana la que debe ser protegida. También el resto de las especies merecen por sí mismas análogo respeto y seguir viviendo, aunque de ello no se derive interés o bien alguno para el ser humano. Es necesario y urgente el reencuentro con la naturaleza, cambiar de tema de conversación, cambiar los diferenciales emocionales asociados a los temas; es necesario cambiar el sentido del gusto (García Carrasco, 2007), mirar y acercarnos a la naturaleza de "otra manera". Somos naturaleza, y esto forma parte de nuestra condición. Los planteamientos pedagógicos hechos sobre el paradigma antropocéntrico resultan del todo insuficientes si se quiere "salvar" la naturaleza.

No sólo vivimos "de", sino "junto a" los seres vivos terrestres, escribe Gómez-Heras, 2000, 196-97). No somos amos y señores (sigue diciendo el autor), sino sus aliados. Compartimos un destino, que en gran parte es fraguado por nosotros y que reclama, por tanto, de nosotros, prudencia, cautela y lucidez a la hora de evaluar cómo intervenir en la naturaleza y hasta dónde. Nos insta a una intervención sostenible, controlada. Apenas conocemos las claves del funcionamiento de la vida, ni de las complejas interrelaciones que gobiernan los ecosistemas naturales; sólo la osadía temeraria puede llevarnos a actuar como si, efectivamente, nos fuera siempre posible prever cuáles serán las consecuencias futuras de todas nuestras intervenciones en esa vida común.

Si durante muchos años nos hemos dedicado a conocer al hombre y transformar el mundo, de ahora en adelante nos deberíamos dedicar con urgencia a hacernos cargo del hombre y del mundo.

\section{Bibliografía}

AzCÁrate, B. y Mingorance, A. (2003) Energias e impacto ambiental. Madrid, Milenium. Beck, U. (2001) La sociedad del riesgo. Barcelona, Paidós.

Bellver, V. (2000) Las ecofilosofías, en Ballesteros, J. y Pérez Adán, J. (eds.). Sociedad y medio ambiente. Madrid, Trotta, 251-269.

BonnetT, M. (2003a) Nature's Intrinsic Value, The Journal of the Philosophy of Education, vol. 37, n. ${ }^{\circ}$, $629-639$. 
LA DIMENSIÓN ÉTICA DE LA CRISIS MEDIOAMBIENTAL. PROPUESTAS PEDAGÓGICAS

- (2003b) Education for Sustainable Development. Sustainability as a Frame of Mind, Journal of the Philosophy of Education, vol. 37, n. ${ }^{\circ} 4,675-690$.

Brown, L. R. (1997) Del crecimiento al desarrollo sostenible, en Goodland, R.; Daly, H.; EL Serafy, S. y Droste, B. von (comps.). Medio ambiente y desarrollo sostenible. Madrid, Trotta.

CAPra, F. (2002) La trama de la vida. Una nueva perspectiva de los sistemas vivos (4. ${ }^{a}$ ed.). Barcelona, Anagrama.

CARIDE, J. A. y MEIRA, P. A. (2001) Educación ambiental y desarrollo sostenible. Barcelona, Ariel.

Colom, A. (2000) Desarrollo sostenible y educación para el desarrollo. Barcelona, Octaedro.

Esteva, G. (1999) Desarrollo, en Viola, A. (comp.). Antropología del desarrollo. Barcelona, Paidós, 67-101.

Gil Cantero, F. (2008) Ciudadanía y humanidad. La educación en el disenso, Teoría de la Educación. Revista Interuniversitaria, vol. 20, 25-44.

Gómez Gutiérrez, J. M. (2004) La ética ambiental. Puntos de vista ecológicos, en GómezHeras, J. M. ${ }^{a}$ G. ${ }^{a}$ y Velayos, C. (coords.). Tomarse en serio la naturaleza. Madrid, Biblioteca Nueva, 223-255.

Gómez-Heras, J. M. ${ }^{a}$ G. $^{a}$ (1997) El problema de una ética del medio ambiente, en GómezHeras, J. M. ${ }^{a}{ }^{\text {G. }}{ }^{a}$ (coord.). Ética del medio ambiente. Problema, perspectivas, historia. Madrid, Tecnos, 17-70.

- (2000) Introducción: Dignidad de la naturaleza y ética medioambiental, en GómezHeras, J. M. ${ }^{a}$ G. ${ }^{a}$ (comp.). La dignidad de la naturaleza. Ensayos sobre ética y filosofía del Medio Ambiente. Granada, Comares, 1-20.

- (2005) Buscando la felicidad. Bilbao, Desclée De Brouwer.

Habermas, J. (1996) Textos y contextos. Barcelona, Ariel.

JONAS, H. (1995) El principio de responsabilidad. Barcelona, Herder.

MAYOR ZARAgOzA, F. (2001) Un mundo nuevo (2. ${ }^{a}$ ed.). Barcelona, Círculo de LectoresGalaxia Gutenberg-Unesco.

Murga Menoyo, M. ${ }^{a}$ A. (2008) Percepciones, valores y actitudes ante el desarrollo sostenible. Detección de necesidades educativas en estudiantes universitarios, Revista Española de Pedagogía, n. ${ }^{\circ} 240,327-343$.

NAES, A. (1984) A defence of Deep Ecology Movement, Environmental Ethics, 6, 265-270.

ÖHmAn, J. (2006) Pluralism and criticism in environmental education and education for sustainable development: a practical understanding, Environmental Education Research, vol. 12, n. ${ }^{\circ}$ 2, 149-163.

Ortega, P. y Mínguez, R. (2001) La educación moral del ciudadano de hoy. Barcelona, Paidós.

- (2003) Educar para una cultura medioambiental, Revista de Educación (MEC), número extraordinario, 271-294.

PAPASTEPHANOU, M. (2005) Globalisation, Globalism and Cosmopolitanism as an Educational Ideal, Educational Philosophy and Theory, vol. 37, n. ${ }^{\circ} 4,533-551$.

REDClifT, M. (2000) El desarrollo sostenible: necesidades, valores, derechos, en BÁrCENA, I.; Ibarra, P. y Zubiaga, M. (eds.). Desarrollo sostenible: Un concepto polémico. Bilbao, Universidad del País Vasco, Servicio Editorial, 17-38.

Rodríguez, A.; Bernal, A. y UrPi, C. (2005) Retos de la educación social. Pamplona, Eunate.

Rombach, H. (2004) El hombre humanizado. Barcelona, Herder. 
Saura, P. y Hernández Prados, M. a A. (2008) La evolución del concepto de sostenibilidad y su incidencia en la educación ambiental, Teoría de la Educación. Revista Interuniversitaria, vol. 20, 179-204.

Sempere, J. (1999) Necesidades y política ecosocialista, en Riechmann, J. (coord.). Necesitar, desear, vivir. Sobre necesidades, desarrollo bumano, crecimiento económico y sustentabilidad. Madrid, Catarata, 274-290.

Sosa, N. (1990) Ética ecológica. Madrid, Libertarias.

- (2000) Ética ecológica y movimientos sociales, en Ballesteros, J. y Pérez Adán, J. (eds.). Sociedad y medio ambiente (2. ${ }^{\mathrm{a}}$ ed.). Madrid, Trotta, 271-299.

Velayos, C. (2004) ¿Es posible una ciudadanía ecológica?, en Gómez-Heras, J. M. ${ }^{a}$ G. ${ }^{a}$ y Velayos, C. (coords.). Tomarse en serio la naturaleza. Madrid, Biblioteca Nueva, 145-164.

Wiredu, K. (2005) On the idea of a global ethic, Journal of Global Ethics, vol. 1, n. ${ }^{\circ}$, 45-51. 